\title{
The association of serotonin transporter genotypes and selective serotonin reuptake inhibitor (SSRI)-associated sexual side effects: possible relationship to oral contraceptives ${ }^{\dagger}$
}

\author{
Jeffrey R. Bishop ${ }^{1,2 *}$, Vicki L. Ellingrod ${ }^{3}$, Michael Akroush ${ }^{1}$ and Jessica Moline ${ }^{3}$ \\ ${ }^{1}$ Department of Pharmacy Practice, College of Pharmacy, University of Illinois at Chicago, Chicago, Illinois, USA \\ ${ }^{2}$ Department of Psychiatry, Center for Cognitive Medicine, College of Medicine, University of Illinois at Chicago, Chicago, Illinois, USA \\ ${ }^{3}$ Department of Psychiatry, University of Michigan College of Pharmacy and College of Medicine, Ann Arbor, Michigan, USA
}

\begin{abstract}
Objective To study the relationship between functional variants in the serotonin transporter gene (SLC6A4) and selective serotonin reuptake inhibitor (SSRI)-associated sexual dysfunction.

Methods One hundred fifteen subjects aged 18-40 years and currently being treated with an SSRI for depression were assessed for clinical variables known to affect sexual well-being. SSRI-associated sexual difficulties were assessed with the Changes in Sexual Functioning Questionnaire (CSFQ). Subjects were subsequently genotyped for the SLC6A4 promoter region (5HTTLPR) insertion/deletion variant and a variable number of tandem repeats (VNTR) in the second intron.

Results The 5HTTLPR insertion/deletion variant was associated with sexual dysfunction in this study sample [odds ratio $(\mathrm{OR})=2.7 ; 95 \%$ confidence interval (CI) 1.2, 6.4; $p=0.02$ ]. The relationship between promoter genotypes and sexual well-being differed in males and females and was related to whether females were taking an oral contraceptive (OC) medication. Females with the $l l$ genotype were nearly eight times more likely to be categorized as having sexual dysfunction if they were taking OCs, while no relationship was observed in those not taking OCs.

Conclusions These results suggest that a functional variant in the serotonin transporter gene is associated with sexual difficulties in persons taking an SSRI for depression. This relationship may differ by sex and be dependent on OC status in females. Copyright (C) 2009 John Wiley \& Sons, Ltd.
\end{abstract}

KEY WORDS - antidepressant; sexual dysfunction; serotonin transporter; polymorphism

\section{INTRODUCTION}

Sexual dysfunction is a common and disconcerting side effect of selective serotonin reuptake inhibitors (SSRIs) that influences a patient's desire to continue long-term antidepressant treatment (Bull et al., 2002; Clayton et al., 2002; Montejo et al., 2001b). Studies specifically assessing changes in sexual well-being over time illustrate that the incidence of sexual side effects from SSRIs ranges from 20 to $70 \%$ depending on the characteristics of the study sample assessed (Clayton et al., 2002; Montejo et al., 1996, 2001b; Montejo-Gonzalez et al., 1997). Sexual side effects

* Correspondence to: J. R. Bishop, Department of Pharmacy Practice, College of Pharmacy, The University of Illinois at Chicago, 833 South Wood Street, Room 164 (M/C 886), Chicago, IL 60612, USA. Tel: 312-4133495. E-mail: jbishop@uic.edu

${ }^{\dagger}$ The research was conducted at the University of Iowa. from antidepressants are of significant clinical importance, particularly in young, sexually active patients who do not tolerate changes in sexual functioning (Montejo et al., 2001a). Developing strategies to predict who may be at the highest risk for adverse changes in their sexual well-being is an important step in improving the quality of life and treatment of patients who require antidepressant agents.

Several variables such as substance use/abuse, smoking, marital status, poor health, medication use, and other disease states have all been shown to have a relationship with sexual well-being in either depressed or euthymic individuals (Clayton et al., 2002; Laumann et al., 1999). In addition, variations in sex hormones such as testosterone, estrogen, or prolactin may influence sexual functioning. Generally speaking, these hormones affect the sexual experience independent from SSRIs, although relationships between estrogen and serotonin transporter expression and the binding affinity of serotonin receptors have been 
reported (Benmansour et al., 2009; Cyr et al., 1998; Pecins-Thompson et al., 1998; Wihlback et al., 2004).

The serotonergic actions of SSRIs have been implicated in the development of sexual side effects (Murray, 1998). Pharmacologically, these medications inhibit the serotonin transporter (5HTT) and increase the synaptic latency period of serotonin (5HT) molecules thereby facilitating the modulation of post-synaptic serotonin receptors (Stahl, 1998). Previous investigations indicate that genetic variability in the gene encoding the serotonin transporter (SLC6A4) is related to the general tolerability of SSRIs, but their specific relationship with sexual side effects has not been investigated (Popp et al., 2006; Smits et al., 2007). Therefore, characterizing the relationship(s) between SLC6A4 and other genetic variations in the serotonin system with SSRIassociated sexual difficulties is an avenue of research that may allow us to develop prediction models of sexual side effects.

To our knowledge, only one other pharmacogenetic study of SSRI-associated sexual side effects has been reported (Bishop et al., 2006). In that analysis, we discovered a common functional variation in the promoter region of the serotonin-2A receptor gene (HTR2A) with SSRI-associated sexual dysfunction. Therefore, the purpose of the present study was to assess a larger study sample to investigate two common functional variations in SLC6A4 and their relationship to overall sexual well-being after controlling for other clinically relevant variables in a population of persons at low risk for other causes of sexual dysfunction.

\section{MATERIALS AND METHODS}

\section{Subjects}

One hundred fifteen outpatients with depression being treated with an SSRI were recruited for this point prevalence study. Subjects were recruited through local advertisements for a study of "health and well-being" while being treated with any one of the following SSRIs: citalopram, escitalopram, fluoxetine, paroxetine, sertraline, or fluvoxamine for depression. Subject eligibility was determined during telephone screenings where they were also informed that the study would consist of an interview session to determine the efficacy of current antidepressant therapy, buccal cell sample for DNA analysis, and a questionnaire to assess changes in sexual well-being while being treated with an SSRI.

Subjects were included if they had been treated with medication for at least 6 weeks, were between the ages of 18 and 40 years, and did not have problems with sexual desire or functioning before beginning medication. The age range of 18-40 years was chosen to minimize the confounds of age on the presence of sexual difficulties (Montejo et al., 2001a). The presence or absence of impaired sexual desire or functioning prior to beginning current medication treatment was assessed during the screening interview and again during the study assessment period. Potential subjects were excluded if they were taking another medication for depression or any other medication known to affect sexual functioning (e.g., stimulants, hypertension medications, non-SSRI antidepressants, antipsychotics, non-contraceptive hormone therapies, nutritional supplements for sexual enhancement, phosphodiesterase- $\mathrm{V}$ inhibitors for the treatment of sexual difficulties, benzodiazepine use within the past 5 days, or other medication judged at the time of assessment to either positively or negatively influence sexual functioning), if they had any other documented primary axis I diagnosis, cardiovascular disease (i.e., hypertension, congestive heart failure, or coronary artery disease), neurological disorder, diabetes mellitus (type I or II), genitourinary disease, menstrual irregularities, had impaired sexual desire or functioning prior to medication initiation or reported frequent urinary tract infections. Medical charts were systematically reviewed by one of the investigators (JRB) to confirm that subjects met the above entry/inclusion criteria and had a diagnosis of depression.

\section{Assessments}

Subjects were assessed in person at the University of Iowa General Clinical Research Center where they were consented for the study, using an informed consent document approved by the University of Iowa Institutional Review Board (IRB). The procedures followed were in accordance with the ethical standards of the University of Iowa IRB and with the Helsinki Declaration of 1975, as revised in 1983. General assessments included vital signs, height, weight, current medications, and sociodemographic variables previously associated with sexual well-being. These included age, race/ethnicity, marital status, whether the participant had children, years of education, alcohol consumption ( $>$ five times in the past month), smoking status (any smoking within the past 6 weeks), or any reported illicit drug use. Assessments of depression status included the Hamilton Rating Scale for Depression 21 item version (HAMD), Hamilton Rating 
Scale for Anxiety (HAMA), specific SSRI used, dose, and duration of use. Dose categories were designed to evaluate the effect of medication dose on sexual dysfunction. For the purposes of this investigation, "higher" doses of SSRI medication were defined as $\geq 40 \mathrm{mg} /$ day of citalopram, fluoxetine, or paroxetine, $\geq 100 \mathrm{mg}$ /day of sertraline, and $\geq 20 \mathrm{mg}$ /day escitalopram. Dosing characteristics for the study population are included in Table 1. Two of the authors (JRB and $\mathrm{JM}$ ) conducted all of the assessments and interviews. A subset of the participants was simultaneously rated by both investigators during the initial stages of the study to generate interrater reliability estimates using interclass correlation coefficients which were 0.98 for both HAMD and HAMA assessments.

Sexual dysfunction was assessed with the selfadministered Changes in Sexual Functioning Questionnaire (CSFQ) (Clayton et al., 1997a). The CSFQ consists of separate assessments for males and females, and has been validated in healthy and depressed clinic populations, and used in both longitudinal and point prevalence studies of sexual well-being (Clayton, 2002; Clayton et al., 1995, 1997b; Keller et al., 2006). Questions on the CSFQ assess a variety of different causes of change in sexual functioning or desire (e.g., relationship changes, stress level, illness, medications, etc.). Sexual dysfunction is determined by falling below thresholds (47 for males and 41 females on a scale of 14-70), where lower scores are indicative of decreased sexual desire or functioning. The CSFQ also consists of subscales to assess specific aspects of sexual well-being. The pre-defined primary outcome variable for this study was sexual dysfunction in both males and females as defined by falling below the sex-specific total score thresholds mentioned above. Arousal and orgasm subscale measures were secondary outcomes assessed as continuous variables in males and females

Table 1. Antidepressant dosing

\begin{tabular}{llcc}
\hline Medication & $\begin{array}{c}\text { Mean } \\
\text { dose (SD) }\end{array}$ & $\begin{array}{c}\text { Dose category } \\
\text { (\% higher })\end{array}$ & $\begin{array}{c}\text { Dose range } \\
\text { (mg/day) }\end{array}$ \\
\hline Citalopram & $31.4(10.3)$ & 57 & $20-40$ \\
Escitalopram & $15.0(6.9)$ & 39 & $10-40$ \\
Fluoxetine & $29.6(17.4)$ & 24 & $10-80$ \\
Paroxetine & $22.5(10.5)$ & 18 & $10-45$ \\
Sertraline & $77.6(41.4)$ & 41 & $50-200$ \\
\hline
\end{tabular}

${ }^{\mathrm{a}}$ Dose categories were designed to evaluate the effect of medication dose on sexual dysfunction outcomes. For the purposes of this investigation, "higher" doses of SSRI medications were defined as $>20 \mathrm{mg} / \mathrm{day}$ of escitalopram; $\geq 40 \mathrm{mg} /$ day of citalopram, fluoxetine, or paroxetine; and $\geq 100 \mathrm{mg} /$ day of sertraline. separately. Results of the self-administered CSFQ allowed us to categorize whether a subject had sexual dysfunction associated with antidepressant treatment in 101 out of $115(88 \%)$ of subjects, while arousal and orgasm score data were complete in 113 out of 115 $(98 \%)$ and 114 out of 115 (99\%) participants, respectively.

\section{Genotyping}

Genomic DNA was isolated from buccal cells collected with cheek brushes (Cyto-Pak, Medical Packaging Corp., Camarillo, CA, USA) with a previously described protocol (Richards et al., 1993). Two common variations in the serotonin transporter (SLC6A4) gene were the focus of this investigation. These included an insertion/deletion variant in the promoter region (5HTTLPR) and a variable number of tandem repeats (VNTRs) in the second intron (STin2) known to be a regulator of gene transcription (Fiskerstrand et al., 1999; Heils et al., 1996; MacKenzie and Quinn, 1999). A previously described functional variant (rs6311 also known as -1438G/A) in the promoter region of the serotonin-2A receptor gene (HTR2A) was also assessed in these participants, as it has been previously associated with SSRI-associated sexual dysfunction (Bishop et al., 2006). Polymerase chain reaction (PCR) primers and determination of the 5HTTLPR insertion/deletion variant in the SLC6A4 promoter region were done with a previously described method (Heils et al., 1996). STin2 VNTR genotypes were determined using previously described primers (Wendland et al., 2006) with PCR conditions according to the following specifications: $95^{\circ} \mathrm{C}$ for $15 \mathrm{~min}, 94^{\circ} \mathrm{C}$ for $30 \mathrm{~s}, 80^{\circ} \mathrm{C}$ for $15 \mathrm{~s}, 70^{\circ} \mathrm{C}$ for $15 \mathrm{~s}, 60^{\circ} \mathrm{C}$ for $90 \mathrm{~s}$, $80^{\circ} \mathrm{C}$ for $60 \mathrm{~s}$, and a final extension at $80^{\circ} \mathrm{C}$ for $10 \mathrm{~min}$ with $500 \mathrm{nM}$ concentration of each primer. PCR products were visualized by electrophoresis on $3.5 \%$ agarose gels stained with ethidium bromide. The genetic analysis for the HTR $2 A-1438 \mathrm{G} / \mathrm{A}$ variant was done according to previously described method (Bishop et al., 2006).

\section{Data analysis}

Differences in sociodemographic variables between medication categories and genotype groups were determined with Pearson's $\chi^{2}$ or Student's $t$-test/oneway analysis of variance for dichotomous and normally distributed continuous variables, respectively. It was determined $a$ priori that the primary genetic analyses would consist of a comparison of 5HTTLPR $l l$ to 
$l s+s s$ genotype groups. Comparisons of STin2.12/ STin2.12 to STin2.10 or STin2.9 carriers were completed based on previous studies showing relatively higher 5HTT gene transcription in mice and cell lines containing the STin2.12 variant (Fiskerstrand et al., 1999; MacKenzie and Quinn, 1999).

Spearman's correlation coefficients were calculated to identify potential confounders between clinical and demographic characteristics and sexual functioning outcome measures. Univariate logistic regression analyses and Wald $\chi^{2}$ test statistics and $95 \%$ confidence intervals (CIs) were completed to determine the associations of clinical and genetic variables with sexual dysfunction. A multiple logistic regression analysis was then performed to examine the association of 5HTTLPR and STin2 VNTR genotype groups with sexual dysfunction after controlling for gender and HAMD scores, which were the other two participant characteristics significantly associated with sexual dysfunction outcome measures. An exploratory analysis of the relationship of SSRI-associated sexual side effects in females stratified by oral contraceptive (OC) status across 5HTTLPR genotype groups was then completed based on previously described relationships between serotonin function and menstrual hormones (Meston and Frohlich, 2000; Wihlback et al., 2004).

A subset of the subjects included in this analysis was part of a previous study (Bishop et al., 2006) where we reported an association of sexual dysfunction with the HTR2A promoter $-1438 \mathrm{G} / \mathrm{A}$ variant. Although the assessment of HTR2A genotypes was not the primary aim of this study, we conducted a post hoc analysis including HTR2A -1438 genotypes in a final prediction model along with 5HTTLPR genotypes to determine whether these two genetic factors are independent predictors of dysfunction in this study sample. Additional variables of the logistic regression analyses included gender and HAMD scores. The Wald $\chi^{2}$ test statistic was used to determine whether a significant interaction between the two genetic variables was present in the context of a logistic model regression 5HTTLPR $l l, H T R 2 A \mathrm{GG}$, and the interaction term of $l l \times \mathrm{GG}$ on sexual dysfunction.

A study sample size $\geq 96$ was prospectively determined by calculating the total number of subjects needed to detect a $25 \%$ difference in the prevalence of sexual dysfunction between 5HTTLPR $l l$ homozygotes and $l s / s s$ genotype groups using a power of 0.80 , and two-tailed alpha values of $\leq 0.05$ were used as the threshold for statistical significance. SAS JMP version 5.01a (SAS Institute, Inc., Cary, NC, USA, 2002) was used for all statistical analyses.

\section{RESULTS}

One hundred fifteen subjects participated in this study. The prevalence of SSRI-associated sexual dysfunction in the entire study sample was $36 \%$ (36/101). Table 1 summarizes medication-dosing characteristics. Sexual dysfunction (as measured by failing to exceed the gender-specific threshold on the CSFQ Total score) associated with SSRI treatment was reported in $42 \%$ $(32 / 77)$ of females and four out of $20(17 \%)$ males $\left(\chi^{2}=4.9,1 \mathrm{df}, p=0.03\right)$. There were no differences in sexual dysfunction or any CSFQ subscale measure between SSRI medication groups in either the whole population or in gender subgroups. Seventy-three $(63 \%)$ of the participants in this study were receiving a "lower" dose of SSRI. There were no differences in CSFQ outcomes between persons on "lower" or "higher" doses of SSRI. HAMD score was significantly associated with sexual dysfunction in the study sample [odds ratio $(\mathrm{OR})=19.9$; 95\% CI 1.9, 265; $p=0.02]$. In females, there was no relationship with OC status and HAMD scores $(F=0.03,1 \mathrm{df}, p=0.86)$ or the likelihood of being categorized as having sexual dysfunction $\left(\chi^{2}=1.0,1 \mathrm{df}, p=0.31\right)$.

Genotype counts (frequencies) for the 5HTTLPR variant were $47 l l(0.41), 46 l s(0.40)$, and $22 s s(0.19)$, which did not deviate significantly from values expected by Hardy-Weinberg Equilibrium (HWE) $\left(\chi^{2}=3.0,2 \mathrm{df}, p=0.09\right)$. For the STin2 VNTR, genotype counts were 2 (STin2.9/STin2.10), 34 (STin 2.10/STin2.10), 3 (STin 2.9/STin2.12), 38 (STin2.10/ STin2.12), and 38 (STin2.12/STin2.12), which deviated from $\operatorname{HWE}\left(\chi^{2}=10.6,3 \mathrm{df}, p=0.014\right)$. Subject characteristics did not differ significantly between $l l$ and $l s / s s$ genotype groups with the exception of gender, where the $l l$ genotype group contained a higher proportion of females than the $l s / s s$ group (see Table 2). No statistically significant differences in these variables were observed between VNTR genotype groups (see Table 3 ).

The $l l$ genotype was significantly associated with the presence of sexual dysfunction in this study sample $(\mathrm{OR}=2.7 ; 95 \%$ CI $1.2,6.4 ; p=0.02)$, while there was no association of STin2.12/STin2.12 genotype with this outcome $(\mathrm{OR}=1.3 ; 95 \% \mathrm{CI} 0.53,3.0 ; p=0.59)$. After controlling for sex and HAMD scores, subjects carrying the $l l$ genotype remained significantly more likely to be categorized as having sexual dysfunction than persons with a $l s$ or $s s$ genotype $(\mathrm{OR}=2.8 ; 95 \%$ CI $1.1,7.2 ; p=0.03)$. Adjusting for these variables did not influence the significance of the VNTR variant on the likelihood of being categorized as having sexual dysfunction $(\mathrm{OR}=1.4 ; 95 \%$ CI $0.5,3.4 ; p=0.50)$. 
Table 2. Subject characteristics stratified by serotonin transporter promoter insertion/deletion genotype group

\begin{tabular}{|c|c|c|c|c|}
\hline \multirow[b]{2}{*}{ Measure } & \multirow{2}{*}{$\begin{array}{c}\text { Entire study sample } \\
N=115 \\
\text { Mean (SD) }\end{array}$} & \multicolumn{2}{|c|}{$\begin{array}{l}\text { 5HTTLPR promoter insertion/deletion } \\
\text { genotypes ( } l=\text { long, } s=\text { short) }\end{array}$} & \multirow[b]{2}{*}{ Test statistic } \\
\hline & & $\begin{array}{l}l l(\mathrm{~N}=47) \\
\text { Mean }(\mathrm{SD})\end{array}$ & $\begin{array}{l}l s / \mathrm{ss}(\mathrm{N}=68) \\
\text { Mean }(\mathrm{SD})\end{array}$ & \\
\hline Age & $29.2(5.8)$ & $26.0(5.4)$ & $26.3(6.1)$ & $(F=0.05,1 \mathrm{df}, p=0.82)$ \\
\hline HAMD & $5.9(3.2)$ & $5.6(3.3)$ & $6.0(3.1)$ & $(F=0.35,1 \mathrm{df}, p=0.55)$ \\
\hline HAMA & $5.7(3.0)$ & $5.5(3.3)$ & $5.9(2.8)$ & $(F=0.50,1 \mathrm{df}, p=0.48)$ \\
\hline Treatment duration (years) & $1.5(2.2)$ & $1.5(2.3)$ & $1.6(2.0)$ & $(F=0.03,1 \mathrm{df}, p=0.87)$ \\
\hline Measure & $N(\%)$ & $N(\%)$ & $N(\%)$ & \\
\hline \multicolumn{5}{|l|}{ Sex } \\
\hline Female & $87(76)$ & $41(87)$ & $46(68)$ & $\left(\chi^{2}=5.8,1 \mathrm{df}, p=0.03\right)$ \\
\hline \multicolumn{5}{|l|}{ Race } \\
\hline Caucasian & $106(92)$ & $44(94)$ & $62(91)$ & $\left(\chi^{2}=2.3,5 \mathrm{df}, p=0.81\right)$ \\
\hline Hispanic & $4(3)$ & $2(4)$ & $2(3)$ & \\
\hline Asian & $2(2)$ & $1(2)$ & $1(1)$ & \\
\hline African-American & $1(1)$ & $0(0)$ & $1(1)$ & \\
\hline Other & $2(2)$ & $0(0)$ & $2(3)$ & \\
\hline \multicolumn{5}{|l|}{ Marital status } \\
\hline Single & $85(74)$ & $35(74)$ & $50(74)$ & $\left(\chi^{2}=0.013,1 \mathrm{df}, p=0.91\right)$ \\
\hline \multicolumn{5}{|l|}{ Children } \\
\hline$\geq 1$ child & $30(15)$ & $10(21)$ & $6(9)$ & $\left(\chi^{2}=3.6,1 \mathrm{df}, p=0.06\right)$ \\
\hline \multicolumn{5}{|c|}{ Smoker (any smoking within past 6 weeks) } \\
\hline Yes & $15(13)$ & $8(17)$ & $7(10)$ & $\left(\chi^{2}=1.1,1 \mathrm{df}, p=0.40\right)$ \\
\hline \multicolumn{5}{|l|}{ Dose category } \\
\hline Low & $73(63)$ & $30(64)$ & $43(64)$ & $\left(\chi^{2}=0.004,1 \mathrm{df}, p=0.95\right)$ \\
\hline \multicolumn{5}{|l|}{ Medication } \\
\hline Citalopram & $14(12)$ & $5(11)$ & $9(13)$ & $\left(\chi^{2}=1.9,4 \mathrm{df}, p=0.76\right)$ \\
\hline Escitalopram & $36(31)$ & $12(26)$ & $24(35)$ & \\
\hline Fluoxetine & $25(22)$ & $11(23)$ & $14(21)$ & \\
\hline Paroxetine & $11(10)$ & $5(11)$ & $6(9)$ & \\
\hline Sertraline & $29(25)$ & $14(30)$ & $15(22)$ & \\
\hline \multicolumn{5}{|c|}{ Alcohol use ( $>5 \times$ in past month) } \\
\hline Yes & $30(26)$ & $13(28)$ & $17(25)$ & $\left(\chi^{2}=0.10,1 \mathrm{df}, p=0.75\right)$ \\
\hline \multicolumn{5}{|l|}{ Oral contraceptive status } \\
\hline Yes & $48(55)$ & $25(61)$ & $23(50)$ & $\left(\chi^{2}=1.1,1 \mathrm{df}, p=0.39\right)$ \\
\hline
\end{tabular}

HAMA, Hamilton Rating Scale for Anxiety; HAMD, Hamilton Rating Scale for Depression 21 item version; 5HTTLPR, Serotonin transporter gene promoter region.

CSFQ arousal scores were then compared across genotype groups in males and females. Mean (SD) scores, out of a maximum of 15 , were 9.5 (2.5) and 9.6 (2.4) for females in $l l$ and $l s / s s$ genotype groups, respectively $(F=0.04,1 \mathrm{df}, p=0.85)$. For males, arousal scores were 13.3 (1.6) and 11.8 (2.0) for those in the $l l$ and $l s / s s$ genotype groups, respectively $(F=2.9,1 \mathrm{df}, p=0.1)$.

Mean scores on the orgasm subscale of the CSFQ (out of a maximum of 15) were 8.5 (3.4) and 10.2 (2.9) for the $l l$ and $l s / s s$ genotype groups in females $(F=6.7$, $1 \mathrm{df}, p=0.01)$, respectively. For males, scores averaged $12.8(0.8)$ and $10.4(1.9)$ for the $l l$ and $l s /$ ss groups $(F=8.8,1 \mathrm{df}, p=0.007)$, respectively. There were no significant differences in arousal or orgasm scores across STin2 VNTR genotype groups. Arousal scores in females averaged 9.7 (2.2) and 9.5 (2.5) for STin2.12/STin2.12 homozygotes and non-STin2.12 carriers, respectively $(F=0.16,1 \mathrm{df}, p=0.69)$. In males, mean arousal scores were 11.8 (2.3) and 12.3
(1.8) for STin2.12/STin2.12 homozygotes and nonSTin2.12 carriers, respectively $(F=0.43,1$ df, $p=0.52$ ). Orgasm scores in females averaged 9.6 (2.8) and 9.3 (3.5) for STin2.12/STin2.12 homozygotes and non-STin 2.12 carriers, respectively $(F=0.08,1 \mathrm{df}$, $p=0.78$ ). In males, mean orgasm scores were 10.1 (2.1) and 11.3 (1.9) for STin2.12/STin2.12 homozygotes and non-STin2.12 carriers, respectively $(F=2.3,1 \mathrm{df}, p=0.14)$.

Forty-eight of the females with completed CSFQ data in this study were taking OC medications, while 39 were not. These were predominantly estrogen or estrogen/progestin formulations, with three subjects taking depo-progestin-only formulations. The relationship of the 5HTTLPR genotype with sexual dysfunction in these two groups is summarized in Table 4. Briefly, in women taking OCs, those with the $l l$ genotype were nearly eight times more likely to be categorized as having sexual dysfunction $(p=0.007)$, while no significant relationship was observed in those 
Table 3. Subject characteristics stratified by serotonin transporter intron 2 variable number of tandem repeats genotype group

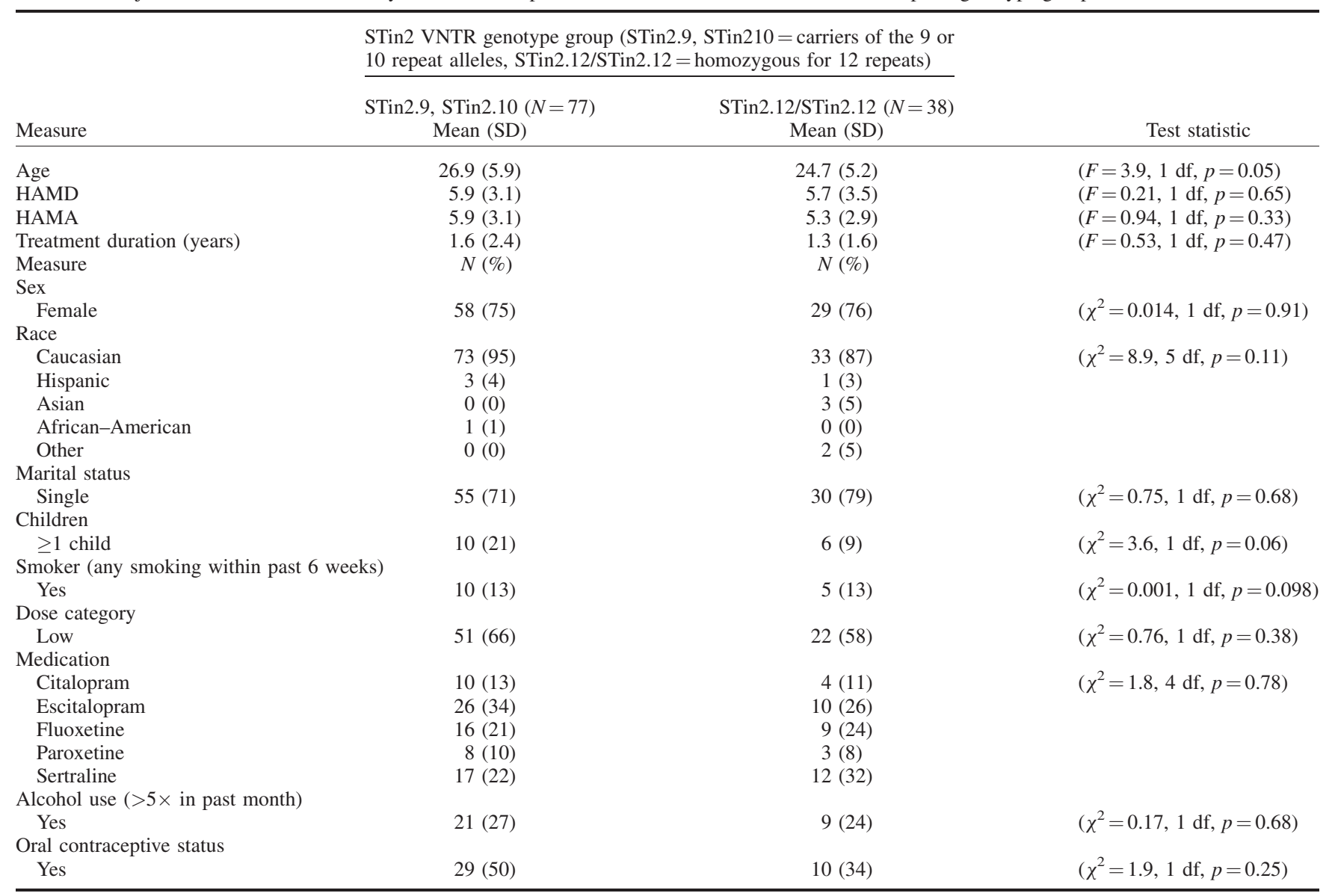

HAMA, Hamilton Rating Scale for Anxiety; HAMD, Hamilton Rating Scale for Depression 21 item version; 5HTTLPR, serotonin transporter gene promoter region.

not taking OCs $(p=0.42)$. When the CSFQ arousal and orgasm subscale measures were assessed, scores did not differ based on OC status (both $p$ s $>0.30$ ). The relationship of these subscale outcomes based on OC status was then stratified by 5HTTLPR genotype group. For females taking OCs, arousal scores averaged $9.2(2.8)$ and $9.4(2.2)$ in the $l l$ and $l s / s s$ groups, respectively $(F=0.14,1 \mathrm{df}, p=0.71)$. Arousal scores in females not taking OCs averaged 10 (2.1) and 9.7 (2.5) for $l l$ and $l s / s s$ groups $(F=0.11,1 \mathrm{df}$,

Table 4. Relationship of serotonin transporter genotypes with sexual dysfunction in females taking oral contraceptives

\begin{tabular}{lrcl}
\hline & \multicolumn{2}{c}{ Taking oral contraceptives $(n=41)$} & \\
Genotype & OR & $95 \% \mathrm{CI}$ & $p$-value \\
5HTTLPR $l l$ & 7.8 & $1.9,41.0$ & 0.007 \\
& Not taking oral contraceptives $(n=36)$ & \\
Genotype & OR & $95 \%$ CI & $p$-value \\
5HTTLPR $l l$ & 1.7 & $0.45,7.0$ & 0.42 \\
\hline
\end{tabular}

Copyright (C) 2009 John Wiley \& Sons, Ltd. $p=0.74)$, respectively. Orgasm scores averaged 8.0 (2.7) and 10.3 (2.9) for $l l$ and $l s / s s$ groups $(F=8.4,1 \mathrm{df}$, $p=0.006)$, respectively. Orgasm scores in those not taking OCs averaged 9.3 (4.3) and 10.1 (2.9) for $l l$ and $l s / s s$ groups $(F=0.59,1 \mathrm{df}, p=0.45)$.

In a previous publication, we reported a positive association of a functional variant in the serotonin-2A receptor (HTR2A) gene with sexual dysfunction (Bishop et al., 2006). Therefore, in a post hoc assessment of subjects from this study, we conducted a logistic regression analysis including both 5HTTLPR and HTR2A -1438 genotypes while controlling for gender and HAMD scores. In this context, the 5HTTLPR $l l$ and HTR2A -1438 GG genotypes were both significantly associated with sexual dysfunction in this study sample $(\mathrm{OR}=3.2 ; 95 \% \mathrm{CI} 1.3,8.8 ; p=0.02)$ and $(\mathrm{OR}=3.2 ; 95 \%$ CI $1.1,10.0 ; p=0.04)$, respectively. A subsequent model did not indicate that a significant interaction between these two genetic predictors was present (Wald $\chi^{2}=0.80,1 \mathrm{df}, p=0.40$ ). 


\section{DISCUSSION}

The primary finding of this investigation is that the serotonin transporter promoter insertion/deletion genotype is associated with sexual dysfunction in this study sample of subjects aged 18-40 years without other significant risk factors such as other major psychiatric illnesses, medical diagnoses, or medications affecting this outcome. This was assessed with the use of the CSFQ, a tool validated in a similar population as the one assessed here in similar study designs. This relationship between genotypes and sexual dysfunction was still present after controlling for other important variables such as sex and depression symptoms as assessed with the HAMD. No relationships between medication, medication dose category, smoking history, substance use, or other sociodemographic variables were observed. Nor were significant associations between the STin2 VNTR of the serotonin transporter gene and sexual dysfunction outcomes. On further analysis, it appears that the relationship between promoter region genotypes and sexual well-being in the context of SSRI treatment may differ in males and females. Arousal and orgasm scores in males were higher (better) in those with the $l l$ genotype, while in females, those with the $l l$ genotype had significantly lower (worse) scores. Our ability to characterize the exact nature of this relationship in males is limited by the smaller number of males who volunteered to participate in this study and should be the subject of future investigations.

We previously published findings highlighting the relationship of the HTR2A -1438 GG genotype with SSRI-associated sexual dysfunction (Bishop et al., 2006). Therefore, we conducted a post hoc analysis of the HTR2A variant in this larger sample to determine if this relationship was still present and further if there was any interaction with the serotonin transporter variants that were the primary focus of the current investigation. When HTR2A genotypes were added to the logistic regression model including gender, HAMD, and 5HTTLPR genotypes, both HTR2A GG and 5HTTLPR $l l$ genotypes were independent predictors of SSRI-associated sexual dysfunction in this study sample.

Previous investigations of the relationship of 5HTTLPR genotypes with response and side effect outcomes in patients taking SSRIs have largely associated the $l l$ genotype with both better response and fewer side effects in Caucasian study samples (Serretti et al., 2007; Smits et al., 2007). Our primary results, particularly in females as a whole, are therefore contrary to these findings. Interestingly, ovarian hormones may influence serotonergic transmission in the body. Important in the context of the population targeted by our recruitment strategies are previous studies showing that estrogen and progesterone changes throughout the menstrual cycle affect serotonin reuptake and $5 \mathrm{HT}_{2 \mathrm{~A}}$ binding (Wihlback et al., 2004). Recent reports suggest that 5HTT expression may differ between males and females based on methylation differences (Philibert et al., 2007) and furthermore that ovarian hormones may affect the binding of SSRIs to 5HTT (Benmansour et al., 2009).

We found no relationship between OC status and mood or sexual well-being in the absence of stratification by 5HTTLPR genotypes. However, the relationship of 5HTTLPR genotype status to SSRIassociated sexual dysfunction in females appears to differ based on whether females were taking an OC medication. Specifically, there was no genotype-sexual dysfunction relationship in females not taking OCs, while those taking OCs were nearly eight times more likely to be categorized as having SSRI-associated sexual dysfunction if they were homozygous 5HTTLPR $l l$. Further, this appears to be driven by differences observed in the CSFQ orgasm subscale, where significant differences were observed across 5HTTLPR genotype groups in females taking OCs. A difference in arousal scale scores across genotype groups was not observed in women when they were stratified by OC status. The reasons for this are unclear. However, serotonin functioning has been related to orgasm difficulties in both males and females and is deleteriously affected by SSRIs in some patients (Clayton et al., 2006; Meston and Frohlich, 2000). In non-human primates, treatment with $\mathrm{OC}$ formulations has been shown to reduce the expression of serotonin transporter mRNA (Bethea et al., 1998). Perhaps the effect of serotonin transporter expression by OCs differs based on 5HTTLPR genotype, which has also been shown to affect gene expression (Bradley et al., 2005; Philibert et al., 2007). Our ability to further examine this relationship and its underlying mechanisms are limited in the context of the present investigation.

The enrollment of female subjects was done without inquiry of time of menstrual cycle, although irregular menses was an exclusion criterion. While we did not prospectively match females based on OC status, there were not significant differences in variables influencing SSRI-associated sexual difficulties such as HAMD scores or other sociodemographic variables examined with the exception of age. Women not taking OCs were on average about 3 years older than those who were taking OCs (24.4 vs. 27.7 years) which while 
statistically different $(p=0.004)$ is not likely to be clinically significant in the context of this study. Age was not a significant predictor of SSRI-associated sexual difficulties in the present sample although it is known that individuals older than 40 years are more likely to have sexual difficulties than younger individuals for a variety of physiological, medical, and environmental reasons (Clayton et al., 2002), which does not explain the relationship seen here. It is possible that some unknown or uncollected characteristics of women taking OCs and those who were not may explain these results, but we feel that this is unlikely, particularly in the context of this study of persons at low risk for sexual difficulties other than taking an antidepressant. Additionally, the documented relationship between serotonin and ovarian hormones is consistent with our findings (Benmansour et al., 2009; Pecins-Thompson et al., 1998; Wihlback et al., 2004).

When interpreting the results of this study, there are other important aspects that warrant consideration. We attempted to minimize the potential confounding effects of depressive symptoms on sexual functioning, by enrolling subjects who had been on SSRIs for at least 6 weeks, in order for them to have an adequate chance to respond to medication. While this was obviously achieved in our study (mean HAMD scores $=5.9$ ), we may have missed subjects who discontinued an SSRI before 6 weeks because of sexual side effects. It is our opinion that missing these subjects is more likely to have diluted the effect that was seen in this sample than result in a spuriously positive outcome. It should also be noted that while we required a minimum of 6 weeks of SSRI treatment for study entry, the treatment duration was variable in our population. It is possible that some of the subjects may have had a gradual improvement in their sexual functioning over time, which could have also lowered the point prevalence sexual dysfunction values observed and possibly minimized the pharmacogenetic relationship seen. However, sexual difficulties from SSRIs are known to be persistent, with most patients not experiencing improvement or alleviation of this unfortunate side effect over time (Montejo et al., 2001a; Montejo-Gonzalez et al., 1997). Finally, the STin2 VNTR marker assessed in this study sample deviated slightly from HWE, which may be viewed as a source of population stratification. Because our study sample was predominantly composed of Caucasian participants, and the 5HTTLPR variant did not deviate from HWE, it is our feeling that this is not likely due to stratification. One explanation of the presence of more of the variant alleles than are normally observed is that we selected our study participants based on MDD status, and previous reports have suggested that rare VNTR alleles are overrepresented in some depressed populations (Battersby et al., 1996; Ogilvie et al., 1996).

Sexual dysfunction is arguably the most clinically significant and most common SSRI-related adverse event in persons taking these medications. Therefore, identifying who may be at an increased risk for this disconcerting outcome is extremely important. In the present study, we are the first to describe the relationship of 5HTTLPR variants specifically with this outcome as assessed by a validated measure, in a model that also holds when including the previously described relationship with the HTR2A -1438 variant. Moreover, this is the first report to indicate that SSRIassociated outcomes may differ by genotype differently in the context of other commonly used medications like OCs. We utilized a previously validated assessment to determine not only the overall measure of sexual health in these subjects, but also the different aspects of sexual well-being. Our subject population was almost completely devoid of confounding medical and pharmacological confounders, which is extremely rare for this type of investigation. Many studies analyzing sexual dysfunction related to antidepressant therapy do not exclude persons based on concurrent medications or other diagnoses. Although that strategy increases the generalizability of a study, employing that methodology in the current study would have made it extremely difficult to determine the relative effects of genetics and medical variables that play a role in a person's overall state of sexual wellbeing.

In conclusion, we report here that a common genetic variant in the promoter region of the serotonin transporter is associated with SSRI-associated sexual dysfunction. This relationship appears to differ in males and females and may depend on whether a female is taking an OC medication. These results warrant replication in larger study samples but exemplify how pharmacogenetics may eventually allow us to predict important clinically significant adverse events in patients taking SSRI medications.

\section{ACKNOWLEDGEMENTS}

This work was supported by grant RR00059 from the General Clinical Research Centers Program, National Center for Research Resources, and grant K08MH6415802 from the National Institute of Mental Health. 
The authors would like to thank Dr. Anita H. Clayton for the use of the CSFQ.

\section{REFERENCES}

Battersby S, Ogilvie AD, Smith CA, et al. 1996. Structure of a variable number tandem repeat of the serotonin transporter gene and association with affective disorder. Psychiatr Genet 6: 177-181.

Benmansour S, Piotrowski JP, Altamirano AV, Frazer A. 2009. Impact of ovarian hormones on the modulation of the serotonin transporter by fluvoxamine. Neuropsychopharmacology 34: 555-564.

Bethea CL, Pecins-Thompson M, Schutzer WE, Gundlah C, Lu ZN. 1998. Ovarian steroids and serotonin neural function. Mol Neurobiol 18: 87-123.

Bishop JR, Moline J, Ellingrod VL, Schultz SK, Clayton AH. 2006. Serotonin 2A -1438 G/A and G-protein Beta3 subunit C825T polymorphisms in patients with depression and SSRI-associated sexual side-effects. Neuropsychopharmacology 31: 2281-2288.

Bradley SL, Dodelzon K, Sandhu HK, Philibert RA. 2005. Relationship of serotonin transporter gene polymorphisms and haplotypes to mRNA transcription. Am J Med Genet B Neuropsychiatr Genet 136: 58-61.

Bull SA, Hunkeler EM, Lee JY, et al. 2002. Discontinuing or switching selective serotonin-reuptake inhibitors. Ann Pharmacother 36: 578-584.

Clayton A, Keller A, McGarvey EL. 2006. Burden of phase-specific sexual dysfunction with SSRIs. J Affect Disord 91: 27-32.

Clayton AH. 2002. Female sexual dysfunction related to depression and antidepressant medications. Current Women's Health Reports 2: 182-187.

Clayton AH, McGarvey EL, Clavet GJ. 1997a. The Changes in Sexual Functioning Questionnaire (CSFQ): development, reliability, and validity. Psychopharmacol Bull 33: 731-745.

Clayton AH, McGarvey EL, Clavet GJ, Piazza L. 1997b. Comparison of sexual functioning in clinical and nonclinical populations using the Changes in Sexual Functioning Questionnaire (CSFQ). Psychopharmacol Bull 33: 747-753.

Clayton AH, Owens JE, McGarvey EL. 1995. Assessment of paroxetineinduced sexual dysfunction using the Changes in Sexual Functioning Questionnaire. Psychopharmacol Bull 31: 397-413.

Clayton AH, Pradko JF, Croft HA, et al. 2002. Prevalence of sexual dysfunction among newer antidepressants. J Clin Psychiatry 63: 357-366.

Cyr M, Bosse R, Di Paolo T. 1998. Gonadal hormones modulate 5hydroxytryptamine $2 \mathrm{~A}$ receptors: emphasis on the rat frontal cortex. Neuroscience 83: 829-836.

Fiskerstrand CE, Lovejoy EA, Quinn JP. 1999. An intronic polymorphic domain often associated with susceptibility to affective disorders has allele dependent differential enhancer activity in embryonic stem cells. FEBS Lett 458: 171-174.

Heils A, Teufel A, Petri S, et al. 1996. Allelic variation of human serotonin transporter gene expression. J Neurochem 66: 2621-2624.

Keller A, McGarvey EL, Clayton AH. 2006. Reliability and construct validity of the Changes in Sexual Functioning Questionnaire short form (CSFQ-14). J Sex Marital Ther 91: 43-52.

Laumann EO, Paik A, Rosen RC. 1999. Sexual dysfunction in the United States: prevalence and predictors. JAMA 281: 537-544.

MacKenzie A, Quinn J. 1999. A serotonin transporter gene intron 2 polymorphic region, correlated with affective disorders, has allele-dependent differential enhancer-like properties in the mouse embryo. Proc Natl Acad Sci U S A 96: 15251-15255.
Meston CM, Frohlich PF. 2000. The neurobiology of sexual function. Arch Gen Psychiatry 57: 1012-1030.

Montejo-Gonzalez AL, Llorca G, Izquierdo JA, et al. 1997. SSRI-induced sexual dysfunction: fluoxetine, paroxetine, sertraline, and fluvoxamine in a prospective, multicenter, and descriptive clinical study of 344 patients. J Sex Marital Ther 23: 176-194.

Montejo AI, Llorca G, Izquierdo JA, et al. 1996. Sexual dysfunction secondary to SSRIs. A comparative analysis in 308 patients. Actas Luso-Esp de Neurol Psiquiatr Cienc Afines 24: 311-321.

Montejo AL, Llorca G, Izquierdo JA, Rico-Villademoros F. 2001a. Incidence of sexual dysfunction associated with antidepressant agents: a prospective multicenter study of 1022 outpatients. Spanish Working Group for the study of psychotropic-related sexual dysfunction. J Clin Psychiatry 62 (Suppl 3): 10-21.

Montejo AL, Llorca G, Izquierdo JA, Rico-Villademoros F. 2001b. Incidence of sexual dysfunction associated with antidepressant agents: a prospective multicenter study of 1022 outpatients. Spanish Working Group for the Study of Psychotropic-Related Sexual Dysfunction [see comment]. J Clin Psychiatry 62 (Suppl 3): 10-21.

Murray JB. 1998. Physiological mechanisms of sexual dysfunction side effects associated with antidepressant medication. J Psychol 132: 407416.

Ogilvie AD, Battersby S, Bubb VJ, et al. 1996. Polymorphism in serotonin transporter gene associated with susceptibility to major depression. Lancet 347: 731-733.

Pecins-Thompson M, Brown NA, Bethea CL. 1998. Regulation of serotonin re-uptake transporter mRNA expression by ovarian steroids in rhesus macaques. Brain Res Mol Brain Res 53: 120-129.

Philibert RA, Sandhu H, Hollenbeck N, Gunter T, Adams W, Madan A. 2008. The relationship of 5HTT (SLC6A4) methylation and genotype on mRNA expression and liability to major depression and alcohol dependence in subjects from the Iowa Adoption Studies. Am J Med Genet B Neuropsychiatr Genet 147B(5): 543-549.

Popp J, Leucht S, Heres S, Steimer W. 2006. Serotonin transporter polymorphisms and side effects in antidepressant therapy - a pilot study. Pharmacogenomics 7: 159-166.

Richards B, Skoletsky J, Shuber AP, et al. 1993. Multiplex PCR amplification from the CFTR gene using DNA prepared from buccal brushes/ swabs. Hum Mol Genet 2: 159-163.

Serretti A, Kato M, De Ronchi D, Kinoshita T. 2007. Meta-analysis of serotonin transporter gene promoter polymorphism (5-HTTLPR) association with selective serotonin reuptake inhibitor efficacy in depressed patients. Mol Psychiatry 12: 247-257.

Smits K, Smits L, Peeters F, et al. 2007. Serotonin transporter polymorphisms and the occurrence of adverse events during treatment with selective serotonin reuptake inhibitors. Int Clin Psychopharmacol 22: 137143.

Stahl SM. 1998. Mechanism of action of serotonin selective reuptake inhibitors. Serotonin receptors and pathways mediate therapeutic effects and side effects. J Affect Disord 51: 215-235.

Wendland JR, Martin BJ, Kruse MR, Lesch KP, Murphy DL. 2006. Simultaneous genotyping of four functional loci of human SLC6A4, with a reappraisal of 5-HTTLPR and rs25531. Mol Psychiatry 11: 224226.

Wihlback AC, Sundstrom Poromaa I, Bixo M, Allard P, Mjorndal T, Spigset O. 2004. Influence of menstrual cycle on platelet serotonin uptake site and serotonin2A receptor binding. Psychoneuroendocrinology 29: 757766. 